\title{
Actor-network theory: opening the black box of the reasons for the involvement of researchers in the technology transfer process
}

\author{
Marcelo O. Garcia \\ og.marcelo@gmail.com | Federal University of Lavras, Department of Administration and Economics, \\ Lavras- Minas Gerais, Brazil \\ Rodrigo Gava \\ rgava@ufv.br|Federal University of Viçosa, Department of Administration and Accounting, Viçosa - \\ Minas Gerais, Brazil \\ Dany F. Tonelli \\ danytonelli@gmail.com | Universidade Federal de Lavras - Programa de Pós-Graduação em \\ Administração - Caixa Postal 3037 - CEP 37200-000 - Lavras MG \\ Valéria G. P. Brito \\ vgpbrito@gmail.com | Universidade Federal de Lavras - Departamento de Gestão Agroindustrial (DGA) \\ - CEP 37200-000 - Lavras MG
}

\begin{abstract}
The process of technology transfer represents a type of social phenomenon that becomes a black box after its completion. That is, access to the process becomes invisible and obscure. The reasons that lead a public researcher to participate in the technology transfer process represented the main concerns to support the research question, whose derived analysis was based on the theoretical-methodological assumptions of the Actor-Network Theory (ANT). This research contributes to understanding the transfer of technology as a complex phenomenon that features the participation of actors with complex and diverse interests; that is, each technology transfer process is singular in its understanding.
\end{abstract}

Keywords. Technology transfer; innovation; Actor-Network Theory; Researcher/Professor.

Cite paper as: Garcia, M., Gava, R., Tonelli, D., Brito, V., (2018). Actor-network theory: opening the black box of the reasons for the involvement of researchers in the technology transfer process, Journal of Innovation Management, www.open-jim.org, 6(4), 49-72. http://hdl.handle.net/10216/118596; DOI: https://doi.org/10.24840/21830606_006.004_0005 


\section{Introduction}

"Technology transfer" can be understood as a type of relationship between universities and industries, focusing on the mechanisms of patenting and licensing of academic inventions (Mowery et al., 2015). In this process, a university legally passes on its knowledge or technology to an industrial enterprise, while the researcher holds the authorship of the invention. However, researchers do not hold its ownership, which belongs to their corresponding institution and the other organizations involved.

Technology transfer has gained prominence since the 1980s, especially in the United States, where the Bay-Dole Act became a milestone. Some observers associate the increase of the licensing and patenting activities in the US with the Bay-Dole Act, while more critical ones relate it to a shift in the "research culture," which led researchers to produce more applied and technological science (Mowery et al., 2015).

In Brazil, on the other hand, the transformations are more recent. The enactment of the Innovation Law dates from 2004 (Law No. 10.973/2004) before it was renewed in 2016 and regulated in 2018 (Law No. 13.243/2016 and Federal Decree No. 9.283/2018). This legal apparatus adopts provisions concerning the need for a federal university (a scientific and technological institution, STI) to have its own or associated Technology Transfer Office performance (TTO, or the socalled Nuclei of Technological Innovation, NITs), which is in charge of managing and protecting intellectual property (IP). Yet, the Article 6 of the Innovation Law provides that STIs may enter into technology transfer agreements and license for use rights grant or exploitation of creation developed by the institution.

This law has encouraged researchers and STIs to transfer their IP (Garnica et al., 2006; Garnica \& Torkomian, 2009) because it assures both the researcher and their STI a legal and secure way for these actors to participate in the technology transfer process. We must emphasize that this study focuses on the intellectual property protected in the TTO as a means for technology transfer. In Brazil, the technology transfer process involving TTOs is complex, due to the different roles played by public and private actors, and their interactions with technology (invention) and technology transfer.

The literature on technology transfer reports that cultural differences are the main barriers to knowledge transfer (Rajalo \& Vadi, 2017). Although research on technology transfer has gained much attention in the last decade, certain areas are yet to be explored. Technology transfer research in developing countries, both related to intellectual property issues and legislation on innovation, represents a gap to be explored in future research. This study has sought to understand the phenomenon of uploading technology in a context where (1) the innovation law is under construction (a fact proved by the Federal Decree No. 9.283, of February 7, 2018); (2) the transfer processes are few; and (3) companies, especially multinational ones, have little knowledge of the collaboration between universities and the industry.

Our research proposal aligns with the theoretical principles of the Actor-Network Theory (ANT) by analyzing relationships and patterns that might reveal the links between unstable and mutable references that lead researchers to engage in research activities with innovation potential (Latour, 
2005). Along these lines, we aimed to explore the flow of actors, whether human or non-human (artifacts, documents, and other devices), to understand the dynamics of such involvement.

ANT was developed primarily by Bruno Latour, Michel Callon, John Law, and others (Sismondo, 2012), and derived from studies on science and technology (Sismondo, 2010). This theory allows identifying relevant actors (agents, entities, practicing or active) involved in the technology transfer process and understands their actions, interactions and associations with other entities while aiming to form a heterogeneous network (Sismondo, 2010; Santos, 2005). ANT allows pondering about the associations involved in the technology transfer process, hence enabling us to understand a social phenomenon (Tureta, 2011) in which the social element is a non-permanent association (Latour, 2005). Nevertheless, the actors have motivations and interests that drive their actions (Sismondo, 2010), which justifies the need to keep constant attention on them, when involved in a process.

The premise of this study is that the investigated reality is constructed through the practices and interactions of different stakeholders to understand heterogeneous networks of human and nonhuman actors.In this context of encouragement and difficulties regarding the innovation process, this paper aimed to identify under what circumstances the researchers from Minas Gerais universities have participated in the technology transfer process. To guide the actions that may clarify this issue, the purpose of this research is to analyze the participation of researchers in the technology transfer process, exploring the implications of the theoretical and methodological assumptions of the Actor-Network Theory.

The introduction is the first section of the article. The second section presents the theoretical framework and an outline of its fundamental concepts, the third section brings the methodological and approaches to this research, the fourth section describes the test results, and the fifth and final section presents the final remarks.

\section{Theoretical Framework}

Transfer technology through university-industry interaction has been regarded as paramount to a knowledge-based society. It is through this process that expectations are generated to ensure the competitiveness of organizations, and the return of the resources channeled to the creation of scientific and technological knowledge back to the community. The theoretical framework of this study establishes a relationship between the key conceptual axes of the research, such as the technology transfer process, the Actor-Network Theory, and the technology transfer through the lenses of the Actor-Network Theory.

\subsection{Technology Transfer}

Studies on the university-industry collaboration (UIC) process in the context of technological innovation are not recent. The linear model of innovation emerged in the 1940s, at the end of the World War II, and was applied by most industrialized countries, grounded on the belief that innovation occurs through a sequence of independent stages (Lastres \& Cassiolato, 2005).

In the late 1960s, a study named La ciência Y la tecnología en el desarrollo futuro de America Latinawas conducted by Jorge Sábato and Natalio Botana, addressing a strategy for scientific 
and technological development in Latin America, which resulted in the Sabato triangle model (Figueiredo, 1993). "The government has been expected to make up for the lack of incentive for private sector innovation." (Etzkowitz \& Brisolla, 1999, p. 342). The Sabato 'triangle' would be as science policy. The three elements of this model are the government, the productive structure, and the technological/scientific infrastructure. They operate in a system of relationships with multiple and coordinated actions, and each represents a vertex of the triangle (Figueiredo, 1993).

However, a new conceptual organization was proposed by the prospect of the Triple Helix because the Sabato triangle does not explain all relationships established by the three elements (Etzkowitz \& Mello, 2004). This model postulates that the government, the academia, and the industry (companies/enterprises) are actors of equal importance and stay in constant interaction in the broader institutional design. "In this, universities are seen as playing a more central role in the knowledge-based economy." (Martin, 2012, p. 1234). The 'entrepreneurial' university adopts a new mission of contributing to the development and to society.

According to Etzkowitz and Leydesdorff (2000), the National Innovation System (NIS) is underlying and analytically different from the Triple Helix model. The authors claim that in the NIS, the company plays the role of leading innovation, while the Triple Helix approach understands that the academia can play a more significant role in the innovation process, wherein all actors are relevant and inserted in the context of mutual interaction between government, academia, and industry; that is, "where each one tries to improve the performance of the other" (Etzkowitz, 2009, p. 11). Yet, it also explains that the interactions between spheres can be useful to understand the transfer process.

Technology transfer occurs in environments where the inventions have the potential to increase productivity and enable economic and social growth. In Brazil, this process at universities is placed in the context of the innovation system and has three main actors: the researchers, the Technology Transfer Office (TTO), and the company that is to market the technology developed by the university. Siegel et al. (2004) studied the technology transfer process in the US and found out numerous cultural and information barriers to the process between the three types of stakeholders (university administrators, researchers, and company/entrepreneurs), primarily because these actors have different motivations, behave differently, and operate in distinct cultural environments. These, in turn, favor misunderstanding and disagreement (Siegel et al., 2004). It is noteworthy that the position equivalent to the university administrator in Brazil is the TTO coordinator.

A specialized and decentralized TTO is vital to establish a good relationship with the industry because TTO has the potential to minimize potential conflicts of interest (Debackere \& Veugelers, 2005).

It should be emphasized that the cooperation between universities and industry is most needed in developing countries, where universities are the most significant source of knowledge aimed at innovation (Stal et al., 2016). In this sense, Suzigan and Albuquerque (2011) state that the public research institute and/or university has a prominent role in many cases of economic or social success in Brazil.

In Brazil, the Innovation Law of 2004 has encouraged the technology transfer process and the 
creation of business incubators and university spin-offs (Luz et al., 2013). The licensing is carried out by means of a contract, i.e., a legal document that must detail all the rights and obligations of the parties and what has been agreed (Lotufo, 2009; Luz, 2012). Licensing is one of the most common mechanisms concerning technology transfer from universities (Stal et al., 2016), which can be explained by the change in legislation and the creation of TTO, patents, university spinoffs, research, joint research, and consultancy contracts (D'Este \& Perkmann, 2011). Due to the complexity of the technology transfer process, these contracts can be a barrier to its achievement (Luz, 2012). Yet, such complexity is not exclusive to Brazil; in the US, for example, the private sector has manifested its frustration with the obstacles involved in the technology transfer process, such as disputes that may arise with the university regarding intellectual property rights (Siegel, Waldman, \& Link, 2003).

The context of an entrepreneurial university can be another way to address the technology transfer process. According to this, the university oversees the creation of research and inventions that contribute to the economic and social development of the country when innovation reaches society (Siegel, Waldman, \& Link, 2003), in addition to carrying out teaching, research, and extension activities. Thus, technology transfer from the university to the private sector has been understood as an economic development strategy (Friedman \& Silberman, 2003). This view is present in the Triple Helix model as an extension to teaching and research activity (Etzkowitz, 2009).

The specialized literature also discusses that certain factors motivate organizations to participate in the transfer process. Segatto-Mendes and Mendes (2006) state that a favorable reason for technology transfer, in the Brazilian context, is the companies' access to knowledge developed by qualified professionals who are sponsored by government funds to support research.

Studies in the United States and Europe are grounded on the structured reality of the universityindustry interaction process (Stal \& Fujino, 2013), differently from the Brazilian context. According to these authors, a significant part of the current literature discusses how to improve cooperation between universities and companies and how to make the structure of the Technology Transfer Office (TTO) more efficient. This scenario differs significantly from the Brazilian reality, where the studies still discuss whether university-industry interactions should be encouraged, whether this interaction is positive or negative for the university, and whether the university should patent its intellectual property so that it can be transferred (Stal \& Fujino, 2013).

Technology transfer studies highlight that several barriers may impede collaboration, with cultural differences representing the central gap reported in such works (Davenport, Davies, \& Grimes, 1999; Siegel et al., 2003; Bjerregaard, 2009; Bjerregaard, 2010). Other studies address the importance of intermediaries, knowledge intermediates, knowledge bearers and external actors in the technology transfer process (Yusuf, 2008; Alexander \& Martin, 2013; Steinmo \& Rasmussen, 2016). The work of Villani, Rasmussen, \& Grimaldi (2017) emphasizes the importance of intermediary organizations in universities, including Technology Transfer Offices (TTOs), business incubators (BIs), and Collaborative Research Centers (CRCs). The inter-organizational trust can lower the barriers (Bruneel, D'Este, \& Salter (2010). Sampson (2004) states that there 
is an implicit hypothesis in the transaction cost literature: poor governance in the context of $\mathrm{R} \& \mathrm{D}$ alliances leads to reduced performance.

The technology transfer is a complicated, risky and time-consuming process (Bozeman, 2000) and its complexity can be exemplified (Bozeman, 2000) by the (1) difficulty in establishing boundaries for a technology (knowledge); 2) the difficulty in describing the technology transfer process involving many simultaneous operations; (3) the fact that measuring the impact of a technology is an arduous task. The transfer is not a linear process, but a specific, dynamic one (Bekkers, \& Freitas, 2008; Luz et al., 2013). The technology transfer process should be treated as a singular case.

\subsection{The benefits of ANT to researching technology transfer}

The Actor-Network Theory (ANT) allows understanding that the investigated reality is constructed through the practices and interactions of different actors, which, in turn, makes it possible to understand the heterogeneous networks of human and nonhuman elements (Sayes, 2014). ANT analysis does not derive from previously defined assumptions on the social phenomenon. According to Tureta and Alcadipani (2009: 57), one of this theory's assumptions "is that there is no rigid definition that can be applied in all situations." The slogan or basic rule adopted by ANT is to follow the actors but being careful to observe when these actors multiply or reduce entities (Latour, 2005).

The process of transferring technology from scientific and technological institutions (STIs) is complex, especially in terms of the different roles played by public and private actors, as well as their interactions with technology (invention) and transference. On the other hand, this relationship may facilitate, modify or even prevent the technology transfer process. In this environment, ANT is perceived as a means for understanding a social phenomenon through a vibrant and dynamic lens. According to ANT, organizations and humans have a specific exposure characteristic (Wickramasinghe \& Bali, 2011), similarly to the (human and nonhuman) actors involved in the technology transfer process. For this reason, ANT can be used to be the theoretical framework that enables the understanding of the transfer process.

ANT allows understanding the process of technology transfer as a complex and dynamic phenomenon, consisting of several operations, some of which may co-occur. This approach favors the meticulous analysis of the phenomena. Therefore, ANT enables a detailed understanding of the actions and roles assumed and performed by each actor, a detailed description of the phenomenon, as well as a global understanding of the technology transfer process.

\subsection{Technology transfer through the lenses of Actor-Network Theory}

In Actor-Network Theory (ANT), actors are heterogeneous and embedded in a network in which they operate and interact to form groups and associations (Sismondo, 2010). ANT has the principle of generalized symmetry as one of its cornerstones, providing that the actors need to be treated by the same vocabulary (Callon, 1986). The notion of symmetry "means for us something broader than that of Bloor: it is essential not only to treat the victors and losers in the history of science in the same terms but also to treat nature and society in the same terms" (Latour \& Woolgar, 1997: 24). For instance, it would be asymmetrical to merely study the reasons 
that hinder technology transfer and not to investigate the reasons favorable to the transfer, believing that the latter case contemplated a natural course of actions and, therefore, needed no understanding (Tonelli et al, 2011). The three principles represent steps that a researcher should take when initiating a study from the ANT perspective.

Translation is another critical concept of ANT and refers to the work that actors, organizations and places negotiate, modify, move and transfer their interests to (Latour, 1999). Translation allows that the identity of the actors involved in technology transfer to be defined and negotiated, and their roles defined.

Inscriptionis another ANT process and refers "to all types of transformations through which an entity becomes materialized into a sign, an archive, a document, a piece of paper, a trace." (Latour, 1999: 306). In this context, the transfer of technology is a means of passing on to society the knowledge derived from an STI and contributing to technological progress and increasing social wealth (Costa \& Torkomian, 2008). Such knowledge is transferred through intermediaries, which are "actors endowed with the capacity to translate what they transport, to redefine it, redeploy it, and also to betray it." (Latour, 1993: 82). Therefore, the mediator creates a network promoting the registration of entities.

The inscription mechanism is the actors' effort to go through the obstacles, hence reaching the Obligatory Passage Point (OPP), that is, the necessary steps to define the problem in the moment of translation, allowing the creation of a network of actors (Kasimin \& Ibrahim, 2011).

The translation and its inscription in "black boxes" (or "black boxing") have allowed the creation of a network of actors. Latour defines the black box as "the way scientific and technical work is rendered invisible by their own success. [...] Paradoxically, the more science and technology are successful, the darker and more obscure they become." (Latour, 1999: 304). When technology works well, its production is emphasized, and its internal complexity is left aside. Thus, transferred science and technology (invention) can be considered as black boxed to be opened by the actor-network theory view, in which the network actors are revealed, as well as their interaction networks.

\section{Methods}

This is a qualitative research study. "Qualitative research is a situated activity that locates the observer in the world. It consists of a set of interpretive and material practices that make the world visible. These practices transform the world." (Denzin \& Lincoln, 2003, p. 4). The notion of worldview, that is, the understanding of the social phenomenon of technology transfer presented in this study was conceived by the Actor-Network Theory (ANT). ANT enables an active worldview (a performance), as it is responsible for directing the theoretical discussion of a study, and also for being essential in the elaboration of the results and discussion section of the present study.

This study focused on an abductive inference, in which the argument "[...] entails considering all possible theoretical explanations for the data, forming hypotheses for each possible explanation, checking them empirically by examining data, and pursuing the most plausible explanation." (Charmaz, 2006, p. 103-104). According to this perspective, abductive inference is a form of 
inference to establish hypotheses capable of interpreting reflexively observed data. This research has been defined as descriptive because it maintains a more significant commitment in the description of the reality analyzed from the discourses of those involved.

The main reason for choosing this specific federative unit is the access to the federal universities based here (the scientific and technological institutions, STIs), to the members of RMPIs (Intellectual Property Associations of Minas Gerais). In fact, the RMPI members constitute the leading research centers in the state of Minas Gerais.

We used primary data and secondary data for research. The first part was collected through semistructured interviews with researchers who participated in the process of technology transfer, as authors or co-authors of the transferred scientific knowledge. The interviews were conducted by means of a script.

The interview script comprised the following topics: (a) to identify the technology transfer context; (b) to identify the government's role in encouraging the technology transfer process; (c) to identify the involvement of the university in the technology transfer process; (d) to identify the performance of the Technology Transfer Office (TTO) in the technology transfer process; and (e) identify the performance of companies in the technology transfer process.

The primary source of secondary data were articles, patents, patent applications, the Lattes curriculum platform and other documents indicated by the studies and their TTO. The combination of the data from these different sources will help to ensure the validity and credibility of the results to be achieved.

The main category of this study deals with the reasons to participate in technology transfer, exploring the implications of the theoretical and methodological frameworks of the ActorNetwork Theory (ANT). To this end, renowned researchers were identified on the national scene. They have either patents or letter patents and are currently working for some STI which is a member of an RMPI. However, only researchers who have participated or are participating in a technology transfer process were included in the sample.

Sampling by subject selection allows researchers to select the members of the population intentionally, according to the characteristics of the study. This paper investigated the three largest TTOs according to the number of technology transfer processes. We studied researchers with great commitment in the context of technological innovation from the Federal University of Minas Gerais (UFMG), Federal University of Viçosa (UFV) and Federal University of Juiz de Fora (UFJF). Nine researchers and four TTO managers were interviewed. We emphasize that due to the complexity of the analysis, we studied three cases of technology transfer per institution.

The analysis was performed on the data from the complete transcriptions of the 13 (Table 1 ) recorded interviews, documents, and observations.

Table 1. Coding List and Interview Time

\begin{tabular}{cc}
\hline Interviewee & Interview time \\
\hline PQ. A.C.A. & $01: 01: 30$ \\
\hline PQ. A.J.V. & $01: 25: 41$ \\
\hline
\end{tabular}




\begin{tabular}{cc}
\hline Interviewee & Interview time \\
\hline PQ. J.C.D.M. & $01: 32: 13$ \\
\hline PQ. J.L.C. & $01: 35: 47$ \\
\hline PQ. J.P.R.F.M. & $01: 08: 14$ \\
\hline PQ. M.M.T. & $01: 52: 04$ \\
\hline PQ. M.P.B. & $02: 32: 21$ \\
\hline PQ. M.V.R. & $01: 52: 50$ \\
\hline PQ. N.R.B.R. & $00: 39: 45$ \\
\hline TTO UFJF & $00: 47: 29$ \\
\hline TTO UFMG & $00: 39: 07$ \\
\hline TTO UFV & $00: 31: 32$ \\
\hline TTO UFV & $01: 11: 30$ \\
\hline TOTAL & $\mathbf{1 6 : 5 0 : 0 3}$ \\
\hline
\end{tabular}

The 13 interviews were recorded using a voice recorder. Upon their completion, the interviews were transcribed. After the analysis of the transcribed interviews, data from each interview were triangulated with data obtained from documentary research and observations.

We resorted to the open coding technique of Strauss and Corbin (2008) because the ANT is a flexible theoretical and methodological approach. The open coding is an analytical process in which concepts are identified, and their properties and dimensions are found in the data (Strauss and Corbin, 2008). Thus, a concept represents a phenomenon of labeling or naming (Strauss \& Corbin, 2008). After we developed the concepts identified in the texts, we proceeded to combine those pertaining to each category. The categories are concepts derived from data, which represent the studied phenomena.

Once the categories have been identified, it is possible for the researcher to develop them in terms of properties and dimensions (Strauss \& Corbin, 2008). For the authors, properties are the characteristics or attributes of a category, whereas the dimensions "represent the location of a property along a line or a lane" (Strauss \& Corbin, 2008, p. 117).

To reach the focus of analysis, empirical data were transformed into texts and analyses through coding techniques that made it possible to build the following categories based on the data (see Figure 1): (a) human commitment; (b) discovery of the object; (c) institutional actor; (d) management of intellectual property; and (e) governmental actor.

The separation between human and non-human actors used in Figure 1 represents only a didactic resource. What exists is the actor's network resulting from the associations and interactions between human and non-human actors. 


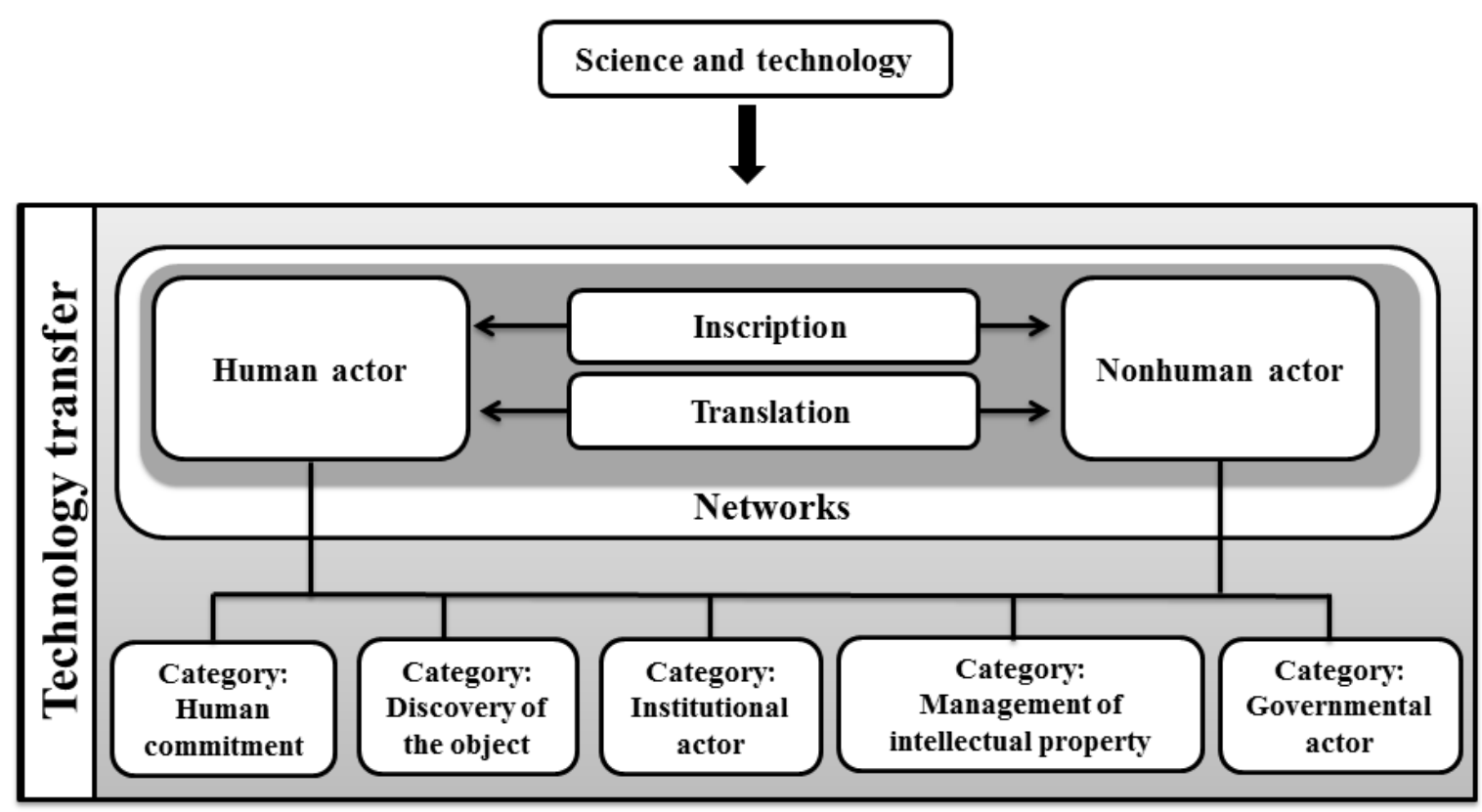

Fig. 1. Analytical scheme

\section{Results and discussion}

\subsection{Research categories}

This section resulted from the organization of the categories of analysis based on ANT, as previously mentioned: (a) human commitment; (b) discovery of the object; (c) institutional actor; (d) management of intellectual property; and (e) governmental actor.

Figure 2 summarizes the main points covered in this article to understand the participation of public researchers in the technology transfer process through the implications of the ANT theoretical and methodological assumptions.

\subsubsection{The "human commitment" category}

The focus of the human commitment categorywas to understand the reasons and motivations that led public researchers to engage in the complex effort of innovation and understand certain specificities that permeate the lives of these individuals. The empirical data that enabled the construction of this category showed that the researcher who participates in the universitybusiness interaction process tends to have the capacity, ability, and vocation to interact with humans and non-human actors present in the context of the scientific activity. We observed that such interactions allow the construction of social networks favorable to the development of basic and/or applied scientific researches.

Our study on the participation of public researchers in the transfer process sought to understand 


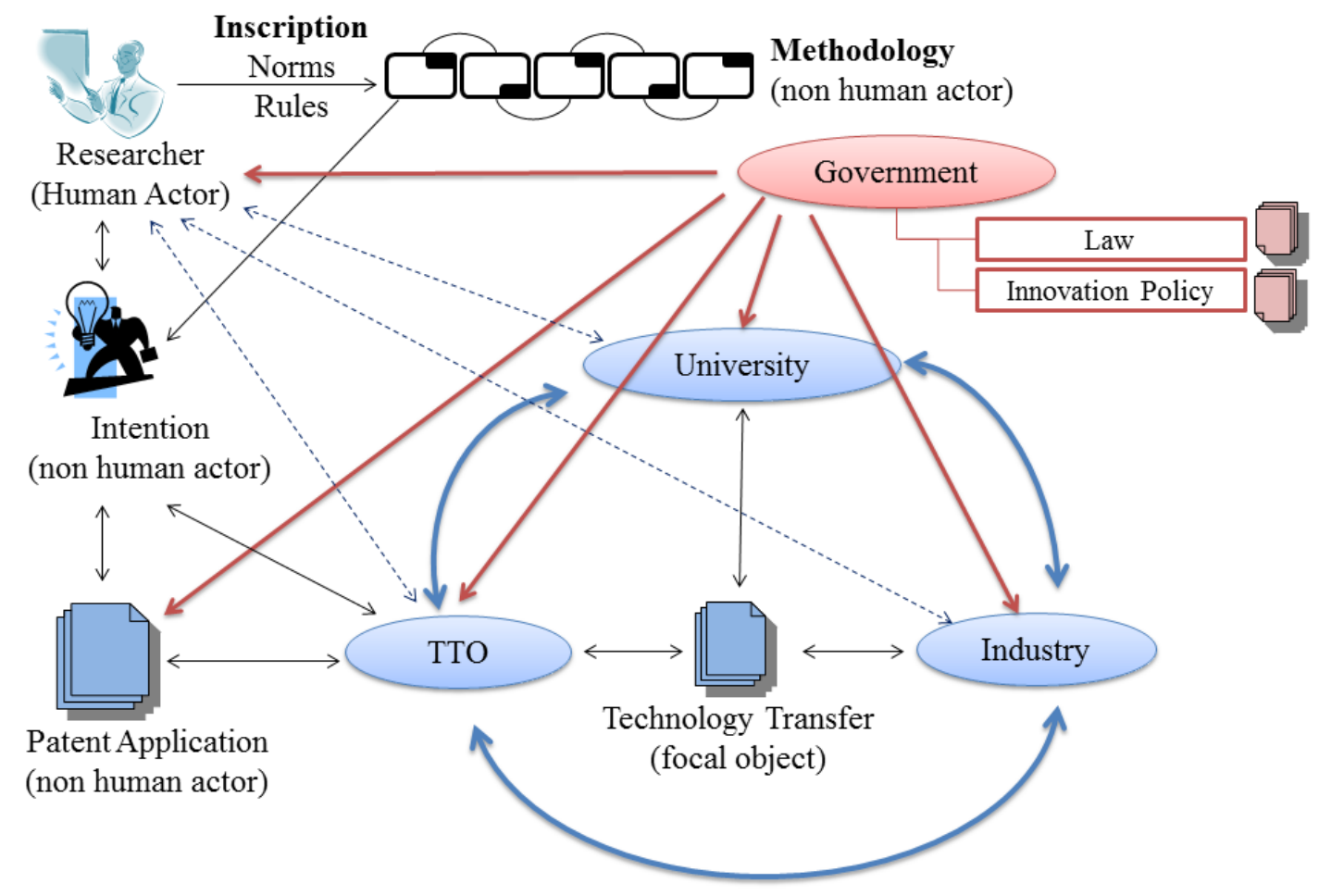

Fig. 2. Summary of the analytical scheme

the scientific activity itself. The daily life and work context of a researcher in a laboratory could be a reported case. Latour and Woolgar (1997) studied the routines of researchers in the Neuroendocrinology Laboratory at Salk Institute.

The researcher/professor can be seen as an emerging, central actor in the human commitment category, wherein their primary reason for engaging in the dynamics of the innovation process refers to their vocation and professional profile (Figure 2). As the first point, we find that vocation is an essential feature and represented the prime motive for the researchers involved in the innovation process. We also observed that the public scientist's career is built through autonomy. The conduct of the professional career is the responsibility of the researcher, and their choices to work with basic or applied research must be respected by society so that these activities are necessary for the development of science. This actor mobilizes and interacts with a variety of human and non-human actors, and new actors have appeared and participated more and more in the inscription and translation processes so as to facilitate technology transfer. This study has focused on the networks that actors formed, aiming at the university-business interaction. It is noteworthy that throughout the innovation process, technology was inserted in the institutional actor category, i.e., on the site or stage where the invention was created.

The professional profile, the research area and its professional practice act as an intrinsic sine qua non, so that the scientist undertakes the complex effort of innovation. We also note that the 
research areas are well-defined and delimited and tend to converge, indicating a more in-depth knowledge of each scientist in a given field.

The motivation for the researcher's commitment to the innovation process was an essential point in this study. The motivation is built and modified throughout one's professional career based on personal interests, the demand of the institution in question, and the opportunities that may arise. This feature is internal and individual for each researcher and may change due to new translations carried out by the subject.

The motivation can also derive from environmental and external causes. The main extrinsic reason for the researcher's commitment to act in the context of innovation was the society's demands or needs. It is noteworthy that researchers guided by the needs of the community are more likely to achieve innovative potential since they move in the same direction as the demands for technological development.

In the process of engaging the researcher in the innovation process, we found that the opportunities provided by a given international experience can act as a sensitizer factor on the performance or cultural change of a given researcher during the innovation process. International expertise can arouse in the researcher the interest in entering agreements with other agents, which may culminate in future interactions with companies and international researchers as well.

The accolades also represent remarkable moments in a researcher's trajectory, as well as the receipt of a letter patent and the first royalties from a licensing. The recognition has the potential to meet the status requirements of researchers and contribute to their motivation to participate in the innovation process.

\subsubsection{The "discovery of the object" category}

As for thediscoveryof the object category, our choice for this title is justified by two things. The first reason refers to the time when the researcher finishes the technological development, i.e., when the invention is created. The second one relates to the replacement of the old dichotomy between subject and object for "a new definition of what it is for a human to deal with what is nonhuman" (Latour, 1999: 108). In this context, the discovery of the object (invention) can also fulfill roles; that is, non-humans may also take action (Latour, 2005).

The invention is another nonhuman actor depicted in Figure 2. The motivation of the researcher to work on the invention process (the discovery of the object), i.e., the device that has been transferred or is going through the transfer process was mainly related to the researcher's area of expertise and the society's demands and needs. The discovery of the object enables the interaction of a researcher with the TTO, the patent application and the industry (that is, the company in question). The result of this cooperation translates into new agreements and mobilizations of actors for the construction of the innovation process. The motivation for creating an invention relates to internal and external factors that permeate the environment in which each technology is produced. Another significant finding is that the primary reason for the engagement into 'object discovery' refers to the researcher's interest, that is, the research field in which they work. 
One of the researchers, who works with scientific instrumentation for nanotechnology, realized that his area needed instruments that are usually imported and costly. He noticed that to conduct cutting-edge research it would be necessary to start developing his own equipment; that is, he identified an opportunity to act.

Another researcher works with photodynamic therapy, and the inscriptions and translations of this actor enabled the development of products and the creation of a university spin-off company. In this context, we noticed that the discovery of the invention represented an Obligatory Passage Point (OPP) for the establishment of such a company. Furthermore, this type of organization can be a potential for an innovation system for inventions developed at universities.

We observed that the motivation for the discovery of the object is driven by external factors. In fact, the main reason for researchers to develop inventions concerns social demands and needs; a researcher illustrates this fact:

The Somos is a creation, so to speak, which came out of a need of the director. I mean, not only the CTIT director but all university managers, who need information; and this information exists in the Lattes platform, so we did something there, which was simply to organize and distribute it in a palatable way to managers [...] It was a demand of CTIT, PRPQ, and UFMG, a necessity which, of course, is familiar to all Brazilian universities and all those who want to manage knowledge (PQ. A.J.V.).

ANT made us realize that the actors (the scientists) were so involved with other actors (the society) that the community led them to conduct studies accordingly. These social mobilizations influenced the researchers and represented the translations. Therefore, the researchers' reports allowed that the network is designed by the translation processes.

The differential of an invention may represent a sine qua nonfor the transfer process. An illustrative example of the differential would be the project for the "Crômic Aerobase" shoes, in which the researcher took part in the development of the cushioning system inspired by cat paws through biomimetics. The walking shoes were created after a company demand, made possible by the initiative of the Federation of the Industries of Minas Gerais State (FIEMG), the Brazilian Micro and Small Business Support Service (SEBRAE), the Euvaldo Lodi Institute (IEL-MG) and the Minas Gerais State Agency for Research and Development (FAPEMIG). UFMG was the institution selected for the development of the walking shoes, which involved laboratories of engineering, physical therapy, and industrial design. The product was developed, transferred to the company and marketed. The researcher sees the export of the product or its technology as a possibility due to its advantages and innovation edge.

\subsubsection{The "institutional actors" category}

The institutional actors are the Minas Gerais federal universities, which in this study are represented by UFJF, UFMG, and UFV. These scientific and technological institutions (STIs) are the places where the inventions are created and where the researchers work, justifying the need to further the understanding of this stage of transactions, agreements, and alliances between actors. 
"Institutional support" refers to the researcher's perception of the university support for innovation, even in the face of its legal and infrastructure limitations. Moreover, since this action occurs through the interaction of the public researcher with the TTO, the data revealed that the TTO tends to understand and be aware of the difficulties and limitations and has aimed to facilitate university-business interaction. The transcript of the interview with a TTO coordinator illustrates this fact.

I think that (...) answering your question (...) it's in our hands, as far as possible, to try and consolidate, you know, and show that this will be a supportive environment, right? (TTO UFMG).

The management addresses the need for the TTO to act as a partner agency for the researchers, so as to be perceived as an adequate place for the protection of intellectual property and technology transfer, although there may be conflicting moments during the negotiations, caused by the existence of laws or internal rules hindering the interaction. Certain agreement clauses may increase the processing and the comings and goings of documents between the University's and the company's attorneys. Added to that, the evaluation and the processing by the attorneys of big enterprises are often time-consuming. From this fact arises the need for large corporations to know the possibilities and clauses that may slow down the innovation process.

The procedures of a given institution may also be perceived as unfavorable to the innovation process by public researchers. The TTO UFV coordinator reports the neutrality or lack of sensitivity by the institution concerning the innovation and the TTO operation.

So, I think it's not worth relying on this (...) I'll tell you something (...) I don't know how important or unimportant I am as the TTO coordinator, or whether the TTO is important or unimportant to everyone who has joined since we've been here (...) I don't know what support we have, because we let it work (...) all our resources come from FAPEMIG (TTO UFV).

It is interesting to note that the gaps and obstacles in public universities are yet to be overcome. We can highlight that the upper management levels need to study innovation in its institution, for it seems that this can minimize or overcome such hindrances. For this strategic study, the involvement of the institution's main spheres is necessary, such as the TTO, its attorneys, the Dean and the Dean of Research Offices, and the incubators.

Our understanding of the institutional environment allowed us to ponder about some complexities in which federal universities are involved by participating in the innovation process. For example, some companies acknowledge that the ownership of technology developed by a public institution due to a technological order belongs exclusively to the applicant organization, but the Brazilian legislation may disallow such arrangement.

\subsubsection{The "management of intellectual property" category}

The management of intellectual propertycategory has emerged from the need for the public researcher to participate in the technology transfer process.

The TTO is a special place that can establish connections with other possible internal and external actors. Initially, we sought to understand the relationships established for innovation 
through the perception of managers and researchers. We noticed that the communication between the TTO and the researchers has enabled the innovation process, as a researcher reports: "The TTO is increasingly responsible not only to act as a facilitator but as a generator as well (...) an inducer for contracts, research agreements between different institutions, and between institutions and companies." (PQ. A.J.V.).

Yet, the TTOs' managers believe that the culture of intellectual property and innovation have been disseminated and understood by researchers, who are beginning to perceive the TTO as a partner agency in this complex context of innovation. However, there are still actions to be taken to improve the performance of this body. Some concern legal, infrastructure and human resources aspects, that is, limitations over which the TTO has little control.

Another understanding is the university-business interaction needs to be established since its inception in the TTO. This behavior minimizes a natural and cultural barrier to this kind of relationship. The TTO, the company, and the researcher have different motivations and practices and even work in different cultural environments, which favors their disagreement (Siegel et al., 2004). In this context, it is relevant that the company and researcher relations are established in the TTO at the very beginning of the interaction.

There is also a perception that the relationship between the TTO and the companies has improved. The TTO is concerned about trying to create a relationship favorable to negotiation, by informing the company of this process and showing that the TTO can facilitate collaboration work cooperatively to affect the innovation process.

Moreover, TTOs' managers believe that when the university-business interaction is performed with companies that have worked in another process, it tends to be facilitated, indicating that the cooperation with partner companies mitigates difficulties because of learning. This confirms Campos et al. (2003), who has stated that innovation processes are characterized by learning.

The construction of a TTO with basic infrastructure at least is a necessity of this actor. Because of that, the TTOs have developed models, resolutions and other instruments that are paramount to their management, allowing to minimize the lack of human resources and staff turnover. We infer that these documents are ANT, not human actors interacting with other actors, enabling the TTO to fulfill its role as the innovation manager.

It is worth noting that in order to achieve innovation, actants need to participate in this process as an actor-network, playing the role of mediators and transcribing what they hold (Latour, 2005). However, actants must meet their needs and enable the development of the innovation system in the country, which is still being formed. There are also more specific obstacles that require sensitivity on the part of the TTO and the company. These must be identified and discussed by the actors to provide the interaction, because, as already mentioned, obstacles that are not identified or overcome may affect the realization of the Obligatory Passage Point (Kasimin \& Ibrahim, 2011) and, therefore, the translations processes.

Despite the flaws and errors, we realized that the TTO is also learning how to be part of this dynamic and at certain moments, its performance will feature mistakes and successes. Thus, 
they should always consider this and create mechanisms to prevent that a previously committed fault may happen again.

\subsubsection{The "government actor" category}

The government actor category consists of the government policy to encourage innovation and the legislation. The innovation policy is materialized by the actions of various actors such as the Ministry of Science, Technology, and Innovation (MCTI), the Financier of Studies and Projects (FINEP), the Secretariat for Economic Development, Science, Technology and Higher Education (SEDECTES) and the Research Support Foundation of the Minas Gerais State (FAPEMIG).

The MCTI performance has been perceived as favorable to the innovation process. In the view of a researcher, the only problems are the slowness of the policy and the fact that it does not follow the need for technological development. Despite its recognition in the context of innovation, MCTI does not produce the effects expected by its stakeholders. This may be because the federal government does not see it as a strategic ministry with the potential to improve the performance of other offices.

In Minas Gerais, SEDECTES has promoted structuring programs to support innovation, and some researchers have noticed its performance. FAPEMIG is perceived as an important governmental agency in the development of state innovation policy, which has mobilized and articulated with other actors to improve its operations, as well as being sensitive and responsible for the implementation and maintenance of the TTO in the state. On the other hand, the activities of FAPEMIG have been criticized for reasons such as the requirement of co-ownership of technology developed with its funding, as reported by Siegel, Waldman, and Link (2003). Another issue concerns the institution's financing policy, which some researchers believe that should comprise projects that require a large number of resources.

National and state laws on innovation have encouraged the university-industry interaction by initially providing a nation-wide innovation system. Yet, the scientific activity concerns a variety of operations that may involve more or fewer laws, permits, benefits, and restrictions. In this context, researchers at public universities must coexist with plurality and diversity in their internal and external environment, which may help to understand why the research activity is peculiar and should often be considered as a single case. Perhaps this is also the reason why Latour (2005: 12) recommends that the ANT's slogan should be "to follow the actors themselves," that is, to understand their innovations, often wild or strange, so as to discover which configurations could explain new associations better.

Researchers understand that the Innovation Law is a remarkable effort to regulate and encourage the matter. However, this law is yet to achieve the desired maturity level to promote universityindustry interaction and thus contribute to the development of the country. We noticed that the TTO performance would be favored with the necessary adjustments, providing greater flexibility and that laws should not be designed only to prevent nation-spread corruption, but instead to encourage scientific and technological research and innovation.

Public funding is the primary resource for research in Brazil. We observed that some researchers 
have no difficulty in obtaining public funding, which may have to do with their field of knowledge, professional performance, or level of achievement in their careers. In fact, public research funding has been considered as a critical factor for research.

The property called "deficiencies in financing" includes the understanding of the limitations of available calls and public funding notices for public researchers. Some researchers point out the need for public funding with higher resource value available to each investigator. Another issue is the financial management of resources, which is somewhat carried out by the researchers themselves or a foundation of management support. Thus, there were cases where the intervener foundation represented an obstacle to the very execution of scientific work.

This study emphasizes that the governmental actor category was involved in every stage of the innovation process. The fact that it represents the policies, actions, and laws aims to encourage the innovation process in the country. The last relevant finding refers to the fact that the TTO has been understood as an essential actor in the promotion of innovation. The TTO is immersed in a context of challenges, difficulties, uncertainties, and risks related to the nature of scientific research, body and law infrastructure. Therefore, this body needs to be strengthened, considering that it is an actor vulnerable to the instabilities of the federal and state governments and the very administration of a scientific and technological institution (STI).

In some institutions, the upper levels of management were not touched by the shortcomings of this body as for its importance. Amid such a complex scenario, where there are obstacles for inventions to become genuine innovations, the figure shows that an OPP will happen. That is, there will be circumstances or crucial moments when the network actors will have to take up a particular role, for example, which contributes to the technology transfer process.

\subsection{The benefits of ANT for the technology transfer process}

This study has shown that the Actor-Network Theory (ANT) and its theoretical and methodological assumptions could support the development, understanding, and adoption of the technology transfer process. This phenomenon is unique and complex and is directly connected to the innovation process, in addition to the technology transfer process being a novel activity to researchers from a public scientific and technological institution (STI) in the country.

There are several benefits to using ANT for technology transfer, including:

- ANT understands that unexpected, new actors may always emerge in the context of the technology transfer process. The managerial implication of this fact is the adoption of flexible, cautious and careful management. For example, new legislation can require a change in contract type.

- After its finalization, the technology transfer process can be compared with the ANT concept of "black boxing." The managerial implication is that project managers should leave all the information organized in order to enable access whenever necessary.

- ANT is appropriate for TTO managers to understand the interests of the researcher and industry (the company) and hence formulate their strategy for technology transfer. The managerial implication is that managers should draw up a detailed contract and to contem- 
plate all the relevant clauses. Inadequate supervision of the elaboration of the agreement may entail fragility in legal disputes.

- In Brazilian public STI, the technology transfer process is complex particularly in the scope of the different roles played by the public and private actors. The managerial implication is that managers should establish a win-win business relationship.

\subsection{Managerial implications}

Business managers must understand that the process of technology transfer in a public university is bounded by a legal framework and internal regulations that provided the guidelines for this process. Laws and regulations may facilitate or limit a transfer process, so TTO and companies' managers need to act as mediators of the process, that is, as agents who bear the knowledge and the ability to promote the technology transfer process.

It should be emphasized that an invention can be understood as a public good or a property of the researcher/professor. The duality between the public good and the property represents a significant bottleneck in the context of innovation. The researcher who understands that the technology developed by them is not a public good can lead to actions in the opposite direction, which is presupposed by the legislation and norms governing a public university. Thus, the researcher can transfer the technology directly to the company, without the involvement of the university. In this case, we emphasize the importance of researchers, industries, and universities becoming aware of intellectual property issues.

The autonomy of a company in the management of its technology portfolio represents another shortcoming in the process of technology transfer. If a company owns an invention jointly with a university, the organization loses part of the autonomy of that particular technology, because the endorsement of the university is required at certain moments. In fact, many companies would like to be able to make a licensing agreement with the assignment of rights, so this issue may represent an obstacle to the realization of the Obligatory Passage Point, which has the potential to prevent the completion of a technology transfer agreement. The Federal Decree No. $9,283 / 2018$ allows the completion of a technological order contract with the assignment of the intellectual property right. This decree is of utmost importance in enabling the technological order.

\section{Conclusion}

The study on technology transfer process through the lens of the Actor-Network Theory (ANT) has allowed understanding that the professional profile/vocation is an essential trace of the researcher's feature and was the primary motivator for their involvement in the innovation process. Moreover, we realized that the field of knowledge in which they have built their careers could also be considered paramount factors for this engagement.

The career of this individual is constructed through certain autonomy as for their operations, an important factor in conducting their projects and research. Through such independence, 
the choice to participate or not in the innovation process is made and this decision-making space, when preserved, keeps the broad spectrum of research interests among the scientific members.

The Technology Transfer Office (TTO) has been understood as an important actor in promoting innovation, although the context of its work is immersed in challenges, difficulties, uncertainties, and risks concerning the very nature of scientific research and the agency's infrastructure and legislation. The TTOs, in turn, need to be the strengthened, considering that such an actor is vulnerable to the instabilities of the federal and state governments and the scientific and technological institutions (STI) themselves. In some universities, the top management level should provide conditions for the TTO to be formalized and structured.

It must be noted that the TTOs have interacted with their respective attorneys to build tools and models that can legitimize the work of these actors and avoid future problems, such as the output of an experienced attorney on intellectual property (IP) and the entry of another with little experience.

The study of the technology transfer process through the lens of ANT allowed understanding that the key players (researchers, the academia, the TTOs, and the companies) have distinct interests and specificities. The creation of an "invention X" or a technology transfer process is a unique case where all inscription and translation operations are specific to each instance. This fact makes it difficult to generalize this process and create models, so the research and development contract design prepared by a TTO is only an initial document that will later be adapted to the specificity of each interaction.

Regarding ANT, papers like this, focusing on networks of moving agents instead of laboratories, tend to mainly identify the translation processes because these are responsible for tracing networks (Latour, 2005). Inscriptions, however, are harder to be perceived (Callon, 1986; Uden \& Francis, 2011).

Yet, this study has shown a few limitations. We have not been able to observe an innovation process from the materialization of the idea present in a research proposal until the invention is made available on the market. Such a study would require our immersion in laboratories for an extended period, that is, an ethnographic survey lasting more than ten years.

Therefore, future research should focus on mediators of the technology transfer process, so as to identify what skills developed by these actors can enable the success of the university-company interaction.

\section{References}

Alexander, T.A., Martin, D.P., 2013. Intermediaries for open innovation: a competence-based comparison of knowledge transfer office practices. Technol. Forecast. Social. Change80, 38-49.

Bekkers, R., \& Freitas, I. M. B. (2008). Analysing knowledge transfer channels between universities and industry: To what degree do sectors also matter?. Research policy, 37(10), 18371853. 
Bozeman, B. (2000). Technology transfer and public policy: a review of research and theory. Research policy, 29(4-5), 627-655.

Bjerregaard, T., 2010. Industry and academia in convergence: micro-institutional dimensions of R \& D collaboration. Technovation30 (2), 100-108.

Bjerregaard, T. (2009). University-industry collaboration strategies: a micro-level perspective. Eur. J. Innov. Manag. 12 (2), 161-176.

Bruneel, J., d'Este, P., \& Salter, A. (2010). Investigating the factors that diminish the barriers to university-industry collaboration. Research policy, 39(7), 858-868.

Callon, M. (1986). Some elements of a sociology of translation: domestication of the scallops and the fishermen of St Brieuc Bay. In J. Law (Ed.), Power, action and belief: a new sociology of knowledge? (pp.196-223) London: Routledge.

Campos, R. R., Cario, S. A. F., Nicolau, J. A., Vargas, G. (2003). Aprendizagem por interação: pequenas empresas em sistemas produtivos locais e inovativos locais. In M. L. Maciel, H. Lastres, \& J. E. Cassiolato (Eds.), Pequena Empresa: cooperação e desenvolvimento local. (pp. 51-65). Rio de Janeiro: Relume Duramá.

Charmaz, K. Constructing Grounded Theory: A Practical Guide through Qualitative Analysis. London: Sage Publications, 2006.

Costa, L. B., \& Torkomian, A. L. V. (2008). Um Estudo Exploratório sobre um Novo Tipo de Empreendimento: os Spin-offs Acadêmicos. RAC-Revista de Administração Contemporânea, $12(2), 395-427$.

Davenport, S., Davies, J., Grimes, C., 1999. Collaborative research programmes: building trust from difference. Technovation19, 31-40.

D'este, P., \& Perkmann, M. (2011). Why do academics engage with industry? The entrepreneurial university and individual motivations. The Journal of Technology Transfer, 36(3), 316-339.

Debackere, K., \& Veugelers, R. (2005). The role of academic technology transfer organizations in improving industry science links. Research policy, 34(3), 321-342.

Denzin, N., \& Lincoln, Y. S. (2003). Collecting and interpreting qualitative materials. 2. ed. California: Sage Publications

Etzkowitz, H. (2009) Hélice Tríplice: universidade-indústria-governo: inovação em ação. Porto Alegre: EDIPUCRS.

Etzkowitz, H., \& Brisolla, S. N. (1999). Failure and success: the fate of industrial policy in Latin America and South East Asia. Research Policy, 28(4), 337-350.

Etzkowitz, H., \& Mello, J. M. C. (2004). The rise of a triple helix culture: Innovation in Brazilian economic and social development. International Journal of Technology Management $\mathcal{E}$ Sustainable Development, 2(3), 159-171.

Etzkowitz, H., \& Leydesdorff, L. (2000). The dynamics of innovation: from National Systems and "Mode 2" to a Triple Helix of university-industry-government relations. Research Policy, $29(1), 109-123$. 
Figueiredo, P. C. N. O. (1993). "Triângulo de Sábato" e as Alternativas Brasileiras de Inovação Tecnológica. Revista de Administração Pública, 27(3), 84-97.

Friedman, J., \& Silberman, J. (2003). University technology transfer: do incentives, management, and location matter?. The Journal of Technology Transfer, 28(1), 17-30.

Garnica, L. A. \& Torkomian, A. L. V. (2009). Gestão de tecnologia em universidades: uma análise do patenteamento e dos fatores de dificuldade e de apoio à transferência de tecnologia no Estado de São Paulo. Gestão e Produção, 16(4), 624-638.

Garnica, L. A., Oliveira, R. M. D., \& Torkomian, A. L. V. (2006, October). Propriedade intelectual e titularidade de patentes universitárias: um estudo piloto na Universidade Federal de São Carlos-UFSCar. Anais do Simpósio de Gestão da Inovação Tecnológica, Gramado, RS, Brasil, 24.

Kasimin, H., \& Ibrahim, H. (2011). Managing Multi-Organizational Interaction Issues: A Case Study of Information Technology Transfer in Public Sector of Malaysia. In. A. Tatnall (Ed.), Actor-Network Theory and Technology Innovation: Advancements and New Concepts. (pp. 192206). Hershey: Information Science Reference.

Lastres, H. M. M., \& Cassiolato, J. E. (2005). Glossário de Arranjos e Sistemas Produtivos e Inovativos Locais - GASPIL. Rio de Janeiro: RedeSist.

Latour, B. (2005).Reassembling the social: An introduction to actor-network-theory. New York: Oxford university press.

Latour, B. (1999). Pandora's hope: essays on the reality of science studies. Cambridge: Harvard University Press.

Latour, B. (1993). We Have Never Been Modern. Cambridge: Mass., Harvard University Press.

Latour, B., \& Woolgar, S. (1997). A vida de laboratório: a produção dos fatos científicos. Rio de Janeiro: Relume Dumará.

Lotufo, R. A. (2009). A Institucionalização de Núcleos de Inovação Tecnológica e a experiência da Inova Unicamp. In M. E. R. Santo, P. T. M. Toledo, \& R. A. Lotufo (Eds.), Transferência de Tecnologia: estratégia para a estruturação e gestão de Núcleo de Inovação Tecnológica. (pp. 41-74). Campinas: Komedi.

Luz, A. A. (2012). Mecanismos de transferência de tecnologia no processo de formação de spinoffs. Master's thesis, Federal University Paraná, Curitiba, Brazil.

Luz, A. A., Kovaleski, J. L., Andrade, P. P., Zammar, A. \& Stankowitz R. F. (2013). Mecanismos de transferência de conhecimento e tecnologia nas instituições de ensino superior. GEINTECGestão, Inovação e Tecnologias, 3(2), 38-54.

Martin, B. R. (2012). The evolution of science policy and innovation studies. Research Policy, 41(7), 1219-1239.

Mowery, D. C., Nelson, R. R., Sampat, B. N., \& Ziedonis, A. A. (2015). Ivory tower and 
industrial innovation: University-industry technology transfer before and after the Bayh-Dole Act. Stanford University Press.

Rajalo, S., Vadi, M. (2017). University-industry innovation collaboration: Reconceptualization. Technovation, 62-63(1), 42-54.

Sampson, R.C., 2004. The cost of misaligned governance in R\&D alliances. J. Law,Econ. Organ.20 (2), 484-526.

Santos, H. M. (2005). Alinhamento estratégico entre negócio e tecnologia de informação na perspectiva da Teoria Ator-Rede: o caso da internet em um banco brasileiro. Master's thesis, Fundação Getulio Vargas, São Paulo, Brazil.

Sayes, E. (2014). Actor-Network Theory and methodology: Just what does it mean to say that nonhumans have agency? Social Studies of Science, 44(1), 134-149.

Segatto-Mendes, A. P., \& Mendes, N. (2006) Cooperação tecnológica universidade-empresa para eficiência energética: um estudo de caso. RAC-Revista de Administração Contemporânea, special edition, 53-76.

Siegel, D. S., Waldman, D. A., Atwater, L. E., \& Link, A. N. (2004). Toward a model of the effective transfer of scientific knowledge from academicians to practitioners: qualitative evidence from the commercialization of university technologies. Journal of Engineering and Technology Management, 21(1-2), 115-142.

Siegel, D. S., Waldman, D., \& Link, A. (2003). Assessing the impact of organizational practices on the relative productivity of university technology transfer offices: an exploratory study. Research policy, 32(1), 27-48.

Sismondo, S. (2012). Fifty years of The Structure of Scientific Revolutions, twenty-five of Science in Action. Social Studies of Science, 42(3), 415-419.

Sismondo, S. (2010). Actor-Network Theory. In S. Sismondo (Ed.), An Introduction to Science and Technology Studies. (pp. 81-92). Malden: Blackwell Publishing.

Stal, E., Andreassi, T., \& Fujino, A. (2016). The Role of University Incubators in Stimulating Academic Entrepreneurship. Revista de Administração e Inovação, 13(2), 27-47.

Stal, E., \& Fujino, A. (2013, October). A Interação Universidade-Empresa no Brasil: o Que Mudou em 30 Anos? Anais do Congresso Latino-Iberoamericano de Gestão da Tecnologia ALTEC, Porto, Portugal, 15.

Steinmo, M., Rasmussen, E., 2016. How firms collaborate with public research organizations: the evolution of proximity dimensions in successful innovation projects. J. Bus. Res. 69, $1250-1259$.

Strauss, A., \& Corbin, J. (2008). Pesquisa Qualitativa: Técnicas e Procedimentos para o Desenvolvimento de Teoria Fundamentada. Porto Alegre: Artmed.

Suzigan, W. \& Albuquerque, E. M. (2011). The underestimated role of universities for the Brazilian system of innovation. Brazilian Journal of Political Economy, 31(1), 03-30.

Tonelli, D. F., Brito, M. J. D., \& Zambalde, A. L. (2011). Empreendedorismo na ótica da teoria 
ator-rede: explorando alternativa às perspectivas subjetivista e objetivista. Cadernos Ebape.BR, 9 (special edition), 586-603.

Tureta, C. (2011). Práticas organizativas em escolas de samba: o setor de harmonia na produção do desfile do Vai-Vai. Doctoral dissertation. Fundação Getúlio Vargas, São Paulo, Brasil.

Tureta, C., \& Alcadipani, R. (2009). O objeto na análise organizacional: a teoria ator-rede como método de análise da participação dos não-humanos no processo organizativo. Cadernos Ebape. $B R, 7(1), 50-70$.

Uden, L., \& Francis, J. (2011). Service Innovation Using Actor-Network Theory. In A. Tatnall (Ed.), Actor-Network Theory and Technology Innovation: Advancements and New Concepts. (pp. 20-40). Hershey: Information Science Reference.

Villani, E., Rasmussen, E., Grimaldi, R., (2017). How intermediary organizations facilitate university-industry technology transfer: a proximity approach. Technological Forecasting \& Social Change 114, 86-102.

Wickramasinghe, N., \& Bali, R. (2011). The need for rich theory to realize the vision of healthcare network-centric operations: the case for combining ANT and social network analysis. In. A. Tatnall (Ed.), Actor-Network Theory and Technology Innovation: Advancements and New Concepts. (pp. 41-51). Hershey: Information Science Reference.

Yusuf, S., 2008. Intermediating knowledge exchange between universities and businesses. Res. Policy37, 1167-1174. 


\section{Biographies}
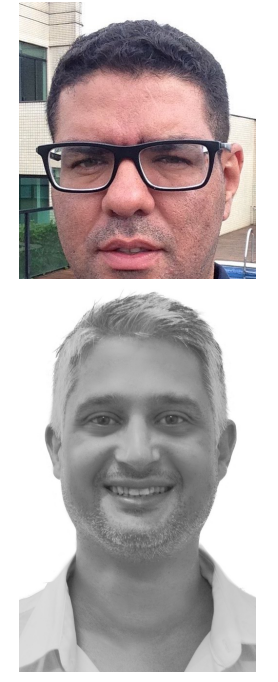

articles.
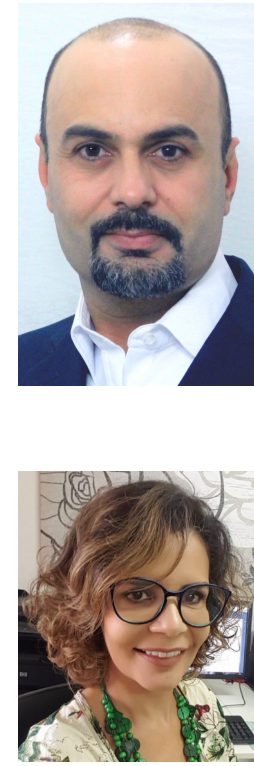

Marcelo O. Garcia. Marcelo de Oliveira Garcia received the B.S. and M.Sc. degrees in Business Administration at Federal University of Viçosa (UFV). He is currently Sc.D candidate in Strategic Management, Marketing and Innovation by the Department of Administration and Economics of the Federal University of Lavras (DAE-UFLA). His main research interests are Organizational Studies, Qualitative Research, Innovation Management and Intellectual Property.

Rodrigo Gava. GAVA, Rodrigo received the B.S. in Administration in 1995, the M.S. in Rural Extension in 2000, both from Universidade Federal de Viçosa (UFV), and the Ph.D. degree in Administration from Brazilian School of Public and Business Administration (FGV/EBAPE), Rio de Janeiro, RJ, in 2009. Since 2002 is Professor with the Administration and Accountability Department, Universidade Federal de Viçosa, where he is also a member of the Post Graduate Program in Public Administration. In 2011 assumes the general coordination of the UFV Technology Transfer Office (CPPI) and the Intellectual Property Association of Minas Gerais State (RMPI), of which he is responsible until today. His research interests embrace the relation between Organizations, Innovation and Development, with special attention on the role of intellectual property rights in it. He is the author of 1 book, 14 book chapters and organized 4 books, in addition to more than 30 articles and 94 conference proceedings

Dany F. Tonelli. Dany Flávio Tonelli holds a Sc.D. in Organizations, Changes, and Strategy by the Federal University of Lavras - Brazil. He was Professor at the Institute of Applied Social Sciences of the Federal University of Alfenas-Brazil between 2009 and 2011 when participated in the consolidation of the Interdisciplinary Degree in Science and Economics. He is currently an Adjunct Professor of Public Administration in the Department of Administration and Economics of the Federal University of Lavras (DAE-UFLA), vice dean of Extension and Culture (PROEC-UFLA), and Coordinator of Technological and Social Development (CODETS-UFLA). He has developed investigations with the emphasis on topics such as (i) innovation in the public sector and innovation policy; (ii) technology-based entrepreneurship in the context of public research institutions; (iii) collaborative arrangements and public management technologies; and (iv) other topics relating science, technology, innovation, and society.

Valéria G. P. Brito. Valéria da Glória Pereira Brito holds a Sc.D. on Administration focusing on Organizations and Society at Federal University of Minas Gerais - Brazil. She has experience in public management and between 2012 and 2016 she was Dean of People Management and Development Affairs. She is currently Associate Professor of Administration in the Department of Agribusiness at Federal University of Lavras - Brazil. Her main research interests are Organizational Studies, Technology, Strategy as Practice, Practice Theory and Qualitative Research. 